\title{
Copolymer-Based Hepatocyte Asialoglycoprotein Receptor Targeting Agent for SPECT
}

\author{
Wenjiang Yang ${ }^{1}$, Tiantian Mou ${ }^{1}$, Guoqiang Shao ${ }^{2}$, Feng Wang ${ }^{2}$, Xianzhong Zhang ${ }^{1}$, and Boli Liu ${ }^{1}$ \\ ${ }^{1}$ Key Laboratory of Radiopharmaceuticals, Ministry of Education, College of Chemistry, Beijing Normal University, Beijing, China; \\ and ${ }^{2}$ Department of Nuclear Medicine, Nanjing First Hospital, Nanjing, China
}

\begin{abstract}
Poly(vinylbenzyl-O- $\beta$-D-galactopyranosyl-D-gluconamide) (PVLA) can be specifically internalized by hepatocytes via the asialoglycoprotein receptor. In this study, we synthesized and characterized galactose-carrying copolymers with hydrazinonicotinamide chains as bifunctional groups to radiolabel PVLA with ${ }^{99 m} \mathrm{Tc}$ for SPECT targeting specific hepatocytes. Methods: Poly $(N-p$-vinylbenzyl-[O- $\beta$-D-galactopyranosyl-( $1 \rightarrow 4)$-D-gluconamide]co- $N$ - $p$-vinylbenzyl-6-[2-(4-dimethylamino)benzaldehydehydrazono]nicotinate) (P(VLA-co-VNI)) was first prepared via copolymerization of $N$ - $p$-vinylbenzyl-O- $\beta$-D-galactopyranosylD-gluconamide with $5 \%$ (mol) of $N$ - $p$-vinylbenzyl-(4-dimethylaminobenzaldehyde hydrazono)nicotinamide. The copolymer was labeled with $99 \mathrm{mTc}$ using tricine as a coligand. Then ${ }^{99 m} \mathrm{Tc}[\mathrm{P}(\mathrm{VLA}-\mathrm{co}-\mathrm{VNI})]$ (tricine) 2 was evaluated by in vivo metabolic stability and biodistribution in normal mice. SPECT was performed in normal New Zealand White rabbits and rabbits with liver cancer. Results: $\left.{ }^{99 \mathrm{~m} T c[P(V L A-c o-V N I)](t r i c i n e)}\right)_{2}$ was prepared in high labeling yield $(>95 \%)$ and radiochemical purity $(>99 \%)$, with good stability. The results of biodistribution in mice demonstrated that the liver uptake was $125.33 \pm 10.99$ percentage injected dose per gram at $10 \mathrm{~min}$ after injection and could be blocked significantly by preinjecting free neogalactosylalbumin or $\mathrm{P}(\mathrm{VLA}-\mathrm{Co}-\mathrm{VNI})$. SPECT images with high quality were obtained at $15,30,60$, and 120 min after injection of the radiotracer. Significant radioactivity defect was observed in the liver cancer model. Conclusion: The bifunctional coupling agent hydrazinonicotinamide was introduced to PVLA via copolymerization and labeled with ${ }^{99 \mathrm{mT}} \mathrm{T}$. The promising biologic properties of ${ }^{99 \mathrm{mT}} \mathrm{Tc}[\mathrm{P}(\mathrm{VLA}-\mathrm{co}-\mathrm{VNI})]$ (tricine) ${ }_{2}$ afford potential applications for the assessment of hepatocyte function in the future.
\end{abstract}

Key Words: asialoglycoprotein receptor; P(VLA-co-VNI); ${ }^{99 m T c ;}$ animal imaging; radiopharmaceuticals

J Nucl Med 2011; 52:978-985

DOI: 10.2967/jnumed.110.085167

\footnotetext{
A sialoglycoprotein receptors (ASGP-Rs) are well known to exist on the mammalian liver (1), situated on

Received Nov. 8, 2010; revision accepted Feb. 18, 2011.

For correspondence or reprints contact either of the following: Xianzhong Zhang, College of Chemistry, Beijing Normal University, 19 Xinjiekou Outer St., Beijing 100875, China.

E-mail: zhangxzh@gmail.com

Boli Liu, College of Chemistry, Beijing Normal University, 19 Xinjiekou Outer St., Beijing 100875, China.

E-mail: liuboli@bnu.edu.cn

COPYRIGHT @ 2011 by the Society of Nuclear Medicine, Inc.
}

the surface of hepatocyte membrane, and participate in the hepatic metabolism of serum proteins. Quantitative imaging of ASGP-Rs could estimate the function of the liver, a unique way to noninvasively diagnose disease. The ASGP-R imaging agent can assess the anatomy and function of the liver and help the early diagnosis of hepatic diseases and accurate evaluation of functional status $(1,2)$. Two other types of radiopharmaceutical are available for liver imaging $(3,4)$ : one type, for hepatobiliary scintigraphy, is labeled lipophilic compounds $\left({ }^{99 \mathrm{~m}} \mathrm{Tc}\right.$-dimethyliminodiacetic acid, ${ }^{99 \mathrm{~m}} \mathrm{Tc}$-diisopropyliminodiacetic acid, and others), which reflect the excretory function of hepatocytes and the abnormalities of the hepatobiliary system. Recently, de Graaf et al. (5) summarized the use of these ${ }^{99 \mathrm{~m}} \mathrm{Tc}$-labeled iminodiacetic acid derivates for the assessment of hepatic function in liver surgery and transplantation and compared them with ASGP-R-based imaging agents. Uptake of labeled lipophilic compounds can be influenced by hepatic blood flow, hypoalbuminemia, and high concentrations of bilirubin (5). The other type of radiopharmaceutical available for liver imaging is labeled colloids $\left({ }^{99 \mathrm{~m}} \mathrm{Tc}\right.$-sulfur colloid and ${ }^{99 \mathrm{~m}} \mathrm{Tc}$-albumin colloid) for colloid scintigraphy, which reflect mainly phagocytic function of the Kupffer cells and evaluate hepatic function indirectly. However, the ASGPR-based imaging agents can be transferred to the hepatocyte via receptor-mediated endocytosis, which is a different principle from the other two types of liver imaging agents. These tracers are affected only by hepatocyte function and cannot be used to diagnose the biliary system but permit a noninvasive way to evaluate hepatic function and hepatic functional reserve directly and quantitatively. ASGP-Rs can recognize galactose or $\mathrm{N}$-acetylgalactosamine residues of desialylated glycoproteins; materials having these ligands have been studied for targeting hepatocytes directly. In the 1980s, neogalactosylalbumin had been developed by attaching the galactosyl unit to human serum albumin (HSA) and then labeling it with ${ }^{99 \mathrm{~m}} \mathrm{Tc}$ for imaging of the liver (6). Later, to simplify the labeling procedure, diethylenetriaminepentaacetic acid (DTPA) galactosyl human serum albumin (GSA) was obtained and developed as an instant kit (7). ${ }^{99 \mathrm{~m} T c-G S A}$ has been used clinically as an ASGP-R-binding radiopharmaceutical in Japan since 1992. The derivates of glycoprotein radiolabeled with ${ }^{99 \mathrm{~m}} \mathrm{Tc}(8-$ 
11), ${ }^{125} \mathrm{I} /{ }^{131} \mathrm{I}$ (12), and ${ }^{111} \mathrm{In}$ (13) have been reported for SPECT applications. ${ }^{68} \mathrm{Ga}$-deferoxamine-neogalactosylalbu$\min (14)$ and ${ }^{18} \mathrm{~F}$-fluorobenzoate galactosyl-neoglycoalbu$\min (15)$ were introduced as PET agents. These agents are similar in that each uses a protein as the backbone for galactose or lactose. Recently, several researchers have reported the use of other polymer backbones, such as dextran and chitosan, instead of proteins to design new probes. Galactosylated dextran or chitosan were able to bind to hepatocytes because of the galactose residue positioned on the exterior of the polymer (16). Radiotracers using dextran or chitosan as the backbone, such as ${ }^{99 \mathrm{~m}} \mathrm{Tc}$-labeled Cy5.5DTPA-galactosyl-dextran (17), ${ }^{99 \mathrm{~m}} \mathrm{Tc}$-galactosyl-methylated chitosan (18), ${ }^{99 \mathrm{~m}} \mathrm{Tc}$-hydrazinonicotinamide-galactosylated chitosan (4), and ${ }^{18} \mathrm{~F}$-fluorobenzoate-galactosylated chitosan (19), have been developed.

The galactose-carrying polystyrene derivative poly $[N-$ $p$-vinylbenzyl- $(O-\beta$-D-galactopyranosyl- $(1 \rightarrow 4)$-D-gluconamide)] (PVLA) has an amphiphilic structural unit composed of hydrophilic oligosaccharide side chains covalently bound to a hydrophobic polystyrene backbone (20). PVLA can be specifically internalized by hepatocytes via the interaction between the ASGP-R and galactose residue of PVLA. PVLA radiolabeled with ${ }^{125} \mathrm{I}$ was reported by Mitsuaki et al. (21). The ${ }^{125}$ I-PVLA was distributed rapidly and mainly to the liver within $15 \mathrm{~min}$ of administration, especially to parenchymal liver cells. In this study, we synthesized and characterized copolymer $\operatorname{poly}(N$ $p$-vinylbenzyl- $[O-\beta$-D-galactopyranosyl- $(1 \rightarrow 4)$-D-gluconamide]-co- $N$ - $p$-vinylbenzyl-6-[2-(4-dimethylamino)benz aldehydehydrazono]nicotinate) $\mathrm{P}(\mathrm{VLA}-\mathrm{co}-\mathrm{VNI})$ and incorporated hydrazinonicotinamide-functionalized groups into PVLA for radiolabeling with ${ }^{99 \mathrm{~m} T c}$.

\section{MATERIALS AND METHODS}

\section{Materials}

All chemicals obtained commercially were used without further purification. Tricine and 4-vinylbenzyl chloride were purchased from J\&K Chemical Ltd. Instant thin-layer chromatography (ITLC) silica gel strips were purchased from Pall Life Sciences. The LabGEN 7 homogenizer was purchased from ColeParmer. Radio-high-pressure liquid chromatography (radio-HPLC) experiments were performed on a system with an SCL-10Avp HPLC pump (Shimadzu Corp.) and a liquid scintillation analyzer (Packard BioScience Co.). The reversed-phase Kromasil C-4 column $(4.6 \times 250 \mathrm{~mm}, 5-\mu \mathrm{m}$ particle size, $30 \mathrm{~nm}$ [300 ̊]; Eka Chemicals) was eluted at a flow rate of $1 \mathrm{~mL} / \mathrm{min}$ according to the procedure described in the Radiochemical Analysis section. The absorbance was monitored at $220 \mathrm{~nm}$. The HiTrap Desalting column (filled with Sephadex G25) was purchased from GE Healthcare, eluted with phosphate buffer $(0.05 \mathrm{~mol} / \mathrm{L} ; \mathrm{pH} 7.5)$. Animal experiments were performed in Kunming mice (female; average weight, $\sim 20 \mathrm{~g}$ ) and New Zealand White rabbits (female; average body weight, $\sim 2.5 \mathrm{~kg}$ ), obtained from the Animal Center of Peking University. All biodistribution studies were performed under a protocol approved by the Beijing Administration Office of Laboratory Animal.

\section{Synthesis of Galactose-Carrying Monomer: VLA}

The $p$-vinylbenzylamine was prepared from 4-vinylbenzyl chloride according to the Gabriel synthesis (22). VLA was synthesized according to the reported method of Kobayashi et al. (23). Briefly, lactobionolactone was dissolved in refluxing methanol, and $p$-vinylbenzylamine solution in methanol was added. The mixed solution was refluxed for $120 \mathrm{~min}$. The white crystal was filtered and purified by recrystallization from methanol.

\section{Synthesis of Hydrazinonicotinamide-Carrying Monomer: VNI}

Succinimidyl 6-[2-(4-dimethylamino)benzaldehydehydrazono] nicotinate was prepared from 6-hydrazinonicotinic acid according to the procedure of Harris et al. (24). $p$-vinylbenzylamine (2.55 mmol) was added to a solution of succinimidyl 6-[2-(4-dimethylamino)benzaldehydehydrazono]nicotinate $(2.65 \mathrm{mmol})$ in $20 \mathrm{~mL}$ of dry dimethyl formamide. The resulting mixture was stirred at room temperature for $24 \mathrm{~h}$. After the reaction, the solvent was removed under reduced pressure, and the residue was suspended in methanol $(3 \mathrm{~mL})$. The solid was collected by filtration, washed with diethyl ether, and dried under a vacuum. The yield was $0.84 \mathrm{~g}$ (82\%). ${ }^{1} \mathrm{H}$ nuclear magnetic resonance (NMR) (400 MHz, dimethylsulfoxide- $\left.\mathrm{d}_{6}\right) \delta: 3.16\left(\mathrm{~s}, 6 \mathrm{H}, \mathrm{N}\left(\mathrm{CH}_{3}\right)_{2}\right), 4.44\left(\mathrm{~s}, 2 \mathrm{H}, \mathrm{N}-\mathrm{CH}_{2}\right)$, $5.22(\mathrm{~d}, 1 \mathrm{H}, \mathrm{H}-\mathrm{C}=\mathrm{C}), 5.79(\mathrm{~d}, 1 \mathrm{H}, \mathrm{H}-\mathrm{C}=\mathrm{C}), 6.73(\mathrm{~m}, 3 \mathrm{H}, \mathrm{H}-\mathrm{C}=\mathrm{C}$ and $N$-phenyl), 7.18 (d, 1H, pyridinyl), 7.29 (d, 2H, phenyl), 7.43 (d, 2H, phenyl), 7.50 (d, 2H, phenyl), 7.97 (s, 1H, pyridinyl), 8.07 (d, $1 \mathrm{H}$, pyridinyl), $8.64(\mathrm{~s}, 1 \mathrm{H}, \mathrm{N}=\mathrm{CH}), 8.85$ (s, 1H, NH-CO), 10.98 (s, $1 \mathrm{H}, \mathrm{NH}-\mathrm{N}=\mathrm{C})$; infrared spectroscopy $(\mathrm{IR})\left(\mathrm{KBr}, \mathrm{cm}^{-1}\right) v: 3454$ $(\mathrm{O}-\mathrm{H}), 1,608(\mathrm{C}=\mathrm{O})$.

\section{Synthesis of Galactose-Carrying Copolymer with Hydrazinonicotinamide Group}

P(VLA-co-VNI) was obtained by a method similar to that used for PVLA (23). Briefly, the mixture of VLA and VNI (5\% mol) was dissolved in dimethylsulfoxide containing azobisisobutyronitrile as an initiator and stirred for $14 \mathrm{~h}$ at $60^{\circ} \mathrm{C}$ to allow copolymerization. The product was precipitated in methanol. The copolymer was dialyzed against water for $24 \mathrm{~h}$ after being dissolved in water (molecular weight cutoff, 8-10 kDa), and the resulting solution was lyophilized.

\section{Preparation of ${ }^{99 \mathrm{~m} T c-L a b e l e d ~ P(V L A-c o-V N I)}$}

To a $10-\mathrm{mL}$ vial, $0.2 \mathrm{~mL}$ of the P(VLA-co-VNI) solution $(0.2$ $\mathrm{mg}$ in phosphate buffer [0.05 mol/L], $\mathrm{pH} 6.0$, about $4.25 \times 10^{-9}$ $\mathrm{mol}), 0.5 \mathrm{~mL}$ of tricine solution $(60 \mathrm{mg} / \mathrm{mL}$ in phosphate buffer [0.05 mol/L], pH 6.0), $10 \mu \mathrm{L}$ of $\mathrm{SnCl}_{2} \cdot 2 \mathrm{H}_{2} \mathrm{O}$ solution $(2 \mathrm{mg} /$ $\mathrm{mL}$ in $\mathrm{HCl}[0.1 \mathrm{~mol} / \mathrm{L}])$, and $0.5 \mathrm{~mL}$ of freshly eluted ${ }^{99} \mathrm{mcO}_{4}{ }^{-}$ from a commercial generator $(\sim 37-370 \mathrm{MBq})$ were added in turn. The vial was sealed and heated for $20 \mathrm{~min}$ at $100^{\circ} \mathrm{C}$ to obtain the resulting complex ${ }^{99 \mathrm{~m}} \mathrm{Tc}[\mathrm{P}(\mathrm{VLA}-\mathrm{co}-\mathrm{VNI})](\text { tricine })_{2}$.

After reaction, the crude product was passed through a $0.22-\mu \mathrm{m}$ Millipore filter and loaded onto a HiTrap desalting column and eluted with phosphate buffer $(0.05 \mathrm{~mol} / \mathrm{L}), \mathrm{pH} 7.5$. After purification, the radiochemical purity (RCP) was evaluated by ITLC chromatography and radio-HPLC.

\section{Radiochemical Analysis}

The chromatography analyses were performed on ITLC silica gel strips with acid-citrate-dextrose buffer (citrate $[0.068 \mathrm{~mol} / \mathrm{L}]$, glucose $[0.074 \mathrm{~mol} / \mathrm{L}], \mathrm{pH} 5.0)$ as a mobile phase. ${ }^{99 \mathrm{~m} T c-l a b e l e d ~} \mathrm{P}$ (VLA-co-VNI) remained at the point of spotting $\left(\mathrm{R}_{\mathrm{f}}=0-0.1\right)$, whereas hydrolyzed ${ }^{99 \mathrm{~m}} \mathrm{Tc}$ and other radioactive impurities moved 
with the solvent front $\left(\mathrm{R}_{\mathrm{f}}=0.8-1.0\right)$. Radio-HPLC was performed on a Shimadzu system with a reversed-phase Kromasil C-4 column $(4.6 \times 250 \mathrm{~mm}, 5 \mu \mathrm{m})$. The column was eluted with $0.1 \%$ trifluoroacetic acid in water (solvent $\mathrm{A}$ ) and $0.1 \%$ trifluoroacetic acid in acetonitrile (solvent $\mathrm{B}$ ) at a flow rate of $1 \mathrm{~mL} / \mathrm{min}$ (gradient: 0-5 min: 95\% A, 5.01-30 min: 70\%-30\% A).

After purification, ${ }^{99 \mathrm{~m}} \mathrm{Tc}[\mathrm{P}(\mathrm{VLA}-\mathrm{co}-\mathrm{VNI})](\text { tricine })_{2}$ was incubated in saline at room temperature for $4 \mathrm{~h}$. The RCP was evaluated by ITLC and radio-HPLC. Plasma stability was determined by ${ }^{99 \mathrm{~m}} \mathrm{Tc}[\mathrm{P}(\mathrm{VLA}-\mathrm{co}-\mathrm{VNI})]$ (tricine) ${ }_{2}$ diluted 20 -fold with freshly prepared murine plasma, and the solutions were incubated at $37^{\circ} \mathrm{C}$ for $4 \mathrm{~h}$. The RCP was evaluated by ITLC chromatography every hour. At the end of $4 \mathrm{~h}$, the plasma was passed through a Sep-Pak $\mathrm{C}_{18}$ cartridge (Waters) and washed with $0.5 \mathrm{~mL}$ of water and eluted with $0.5 \mathrm{~mL}$ of acetonitrile containing $0.1 \%$ trifluoroacetic acid. The combined aqueous and organic solutions were passed through a $0.22-\mu \mathrm{m}$ Millipore filter and evaluated by radio-HPLC.

\section{Metabolic Stability}

Mice were intravenously injected with $7.4 \mathrm{MBq}$ of ${ }^{99 \mathrm{~m}} \mathrm{Tc}[\mathrm{P}$ (VLA-co-VNI)](tricine) 2 (about $4 \times 10^{-9} \mathrm{~mol}$ of polymer $/ \mathrm{kg}$ of body weight). The animals were sacrificed at 10 and $120 \mathrm{~min}$ after tracer injection. Blood, liver, and urine were collected. Blood samples were immediately centrifuged for $5 \mathrm{~min}$ at $13,200 \mathrm{rpm}$. After removal of the supernatants, the pellets were washed with $250 \mu \mathrm{L}$ of phosphate-buffered saline $(\mathrm{pH} 7.5)$. Supernatants of both centrifugation steps were combined and passed through a Sep-Pak $\mathrm{C}_{18}$ cartridge. After washing with saline, the liver samples were homogenized in $4 \mathrm{~mL}$ of phosphate-buffered saline $(\mathrm{pH}$ 7.5) using a polytron homogenizer (LabGEN 7) at full speed for $5 \mathrm{~min}$. The resulting homogenate was centrifuged for $60 \mathrm{~min}$ at $14,000 \mathrm{rpm}$. Supernatants were passed through a Sep-Pak $\mathrm{C}_{18}$ cartridge. The urine samples were directly diluted with $0.5 \mathrm{~mL}$ of phosphate-buffered saline and then passed through a Sep-Pak $\mathrm{C}_{18}$ cartridge. All the cartridges were washed with $0.5 \mathrm{~mL}$ of water and eluted with $0.5 \mathrm{~mL}$ of acetonitrile containing $0.1 \%$ trifluoroacetic acid. The combined aqueous and organic solutions were passed through a $0.22-\mu \mathrm{m}$ Millipore filter and then injected onto radioHPLC using a flow rate of $1 \mathrm{~mL} / \mathrm{min}$ and a gradient as described.

\section{Biodistribution}

The biodistribution study of ${ }^{99 \mathrm{~m}} \mathrm{Tc}[\mathrm{P}(\mathrm{VLA}-\mathrm{co}-\mathrm{VNI})](\text { tricine })_{2}$ was performed in normal mice. About $0.185 \mathrm{MBq}$ (in $100 \mu \mathrm{L}$ of solution) of ${ }^{99 \mathrm{~m}} \mathrm{Tc}[\mathrm{P}(\mathrm{VLA}-\mathrm{co}-\mathrm{VNI})](\text { tricine })_{2}\left(\sim 1 \times 10^{-9} \mathrm{~mol}\right.$ of polymer $/ \mathrm{kg}$ of body weight) was injected through the tail vein. At selected times $(10,30$, and $120 \mathrm{~min})$, mice $(n=5$ at each time point) were sacrificed, and the tissues and organs of interest were collected, wet-weighed, and counted in a $\gamma$-counter. The percentage injected dose per gram $(\% \mathrm{ID} / \mathrm{g})$ for each sample was calculated by comparing its activity with an appropriate standard of ID.

To further confirm that the ${ }^{99 \mathrm{~m}} \mathrm{Tc}[\mathrm{P}(\mathrm{VLA}-\mathrm{co}-\mathrm{VNI})](\text { tricine })_{2}$ had specific receptor binding, a blocking study was performed by conducting the biodistribution experiment in the presence of free neogalactosylalbumin $\left(200 \mu \mathrm{g}, \sim 1.4 \times 10^{-7} \mathrm{~mol} / \mathrm{kg}\right.$ of body weight $)$ and free cold P(VLA-co-VNI) $\left(200 \mu \mathrm{g}, \sim 2.1 \times 10^{-7} \mathrm{~mol} / \mathrm{kg}\right.$ of body weight) as a blocking agent. Five minutes after the first injection of blocking agent, about $0.185 \mathrm{MBq}$ (in $100 \mu \mathrm{L}$ of solution) of $\left.{ }_{99 \mathrm{~m} T c} \mathrm{P}(\mathrm{VLA}-\mathrm{co}-\mathrm{VNI})\right](\text { tricine })_{2}$ was intravenously injected $(\sim 1 \times$ $10^{-9} \mathrm{~mol}$ of polymer $/ \mathrm{kg}$ of body weight). Mice were sacrificed at 10,30 , and 120 min after injection $(n=5)$. Results were expressed as the $\% \mathrm{ID} / \mathrm{g}$. Averages and SD were calculated.

\section{SPECT}

The SPECT/CT (Millennium VG; GE Healthcare) scanner was equipped with a pinhole collimator to acquire planar images. The acquiring parameters were as follows: energy peak of $140 \mathrm{keV}$, window width of $20 \%$, matrix of $256 \times 256$, zoom of 1.0 , and $10 \mathrm{~min} / \mathrm{frame}$. SPECT/CT fusion images were acquired using parallel-hole collimators. New Zealand White rabbits were placed near the center of the field of view of the SPECT scanner, at which the highest image resolution and sensitivity are available. The rabbits were deeply anesthetized by intraperitoneal injection of sodium pentobarbital; anesthesia was supplemented as needed. About 60 $\mathrm{MBq}$ of ${ }^{99 \mathrm{~m}} \mathrm{Tc}[\mathrm{P}(\mathrm{VLA}-\mathrm{co}-\mathrm{VNI})]$ (tricine) $)_{2}\left(\sim 1.7 \times 10^{-9} \mathrm{~mol}\right.$ of polymer $/ \mathrm{kg}$ of body weight $)$ in $1 \mathrm{~mL}$ of phosphate buffer $(0.05 \mathrm{~mol} / \mathrm{L} ; \mathrm{pH}$ 7.5) was injected in the marginal ear vein. Computer acquisition of the $\gamma$-camera data was initiated during administration of the radiopharmaceutical. Time-activity curves for the blood, kidney, and liver were generated by selecting regions of interest around the heart, kidney, and liver. Static images at 15, 30, 60, and $120 \mathrm{~min}$ after the tracer injection were acquired. The scan time was 2 min. For comparison, a blocking study was performed using preinjected free neogalactosylalbumin ( $25 \mathrm{mg}, \sim 1.4 \times 10^{-7} \mathrm{~mol} / \mathrm{kg}$ of body weight) as a blocking agent $5 \mathrm{~min}$ before intravenous injection of the radiotracer.

The liver cancer model was prepared by induced VX2 carcinoma in the liver of rabbits. Tumor size was checked by CT. The rabbits with 2- to $3-\mathrm{cm}$ tumors were included in the experiment. SPECT was performed in the same manner as for the normal group. The SPECT/CT study was performed $30 \mathrm{~min}$ after injection. After imaging studies, pathologic examination was performed to confirm the liver tumor.

\section{Statistical Analysis}

Values are presented as mean $\pm \mathrm{SD}$. An unpaired 2-tailed $t$ test was used to determine statistical significance using GraphPad InStat software (GraphPad Software). A $P$ value of less than 0.05 was considered statistically significant.

\section{RESULTS}

\section{Chemistry}

The monomers of both VLA and VNI were prepared with good yield and characterized by ${ }^{1} \mathrm{H}$ NMR and IR. VLA with VNI were copolymerized with azobisisobutyronitrile as an initiator at $60^{\circ} \mathrm{C}$ for $14 \mathrm{~h}$, as shown in Figure 1. The pale yellow powdery polymers were isolated by freezedrying from the aqueous solution. The P(VLA-co-VNI) was characterized by ${ }^{1} \mathrm{H}$ NMR and elemental analyses. The copolymer composition was estimated from the carbonto-nitrogen $(\mathrm{C} / \mathrm{N})$ mass ratio, which was 14.25 . The ratio of VLA units to VNI units in P(VLA-co-VNI) was about 94:6 (n:m). The theoretic molecular weight of P(VLA-coVNI) was about $47 \mathrm{kDa}$, calculated from the ratio of azobisisobutyronitrile initiator to monomer, and has narrow size distribution (Supplemental Fig. 1; supplemental materials are available online only at http://jnm.snmjournals. org). The number of galactose and hydrazinonicotinamide units per polymer was about 94 and 6, respectively.

\section{Radiochemistry}

The labeling conditions of ${ }^{99 \mathrm{~m}} \mathrm{Tc}[\mathrm{P}(\mathrm{VLA}-\mathrm{co}-\mathrm{VNI})]($ tricine $)_{2}$ were investigated, and optimized conditions were 


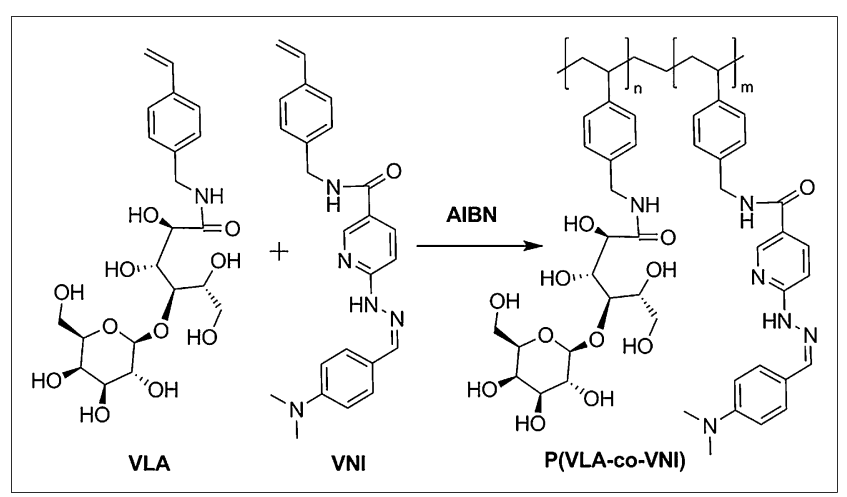

FIGURE 1. Synthesis route of copolymer P(VLA-co-VNI) with galactose and hydrazinonicotinamide group (ratio of VLA units to VNI units was about 94:6 according to the carbon-to-nitrogen $(\mathrm{C} / \mathrm{N})$ mass ratio of $\mathrm{P}(\mathrm{VLA}-\mathrm{Co}-\mathrm{VNI}))$. AIBN = azobisisobutyronitrile.

obtained under $\mathrm{pH} 6.0$ for $20 \mathrm{~min}$ at $100^{\circ} \mathrm{C}$. The labeling yield was greater than $95 \%$. After rapid purification with a HiTrap desalting column, the RCP of ${ }^{99 \mathrm{~m} T c[P(V L A-c o-}$ VNI)](tricine) ${ }_{2}$ was more than $99 \%$, as determined by ITLC and radio-HPLC. The HPLC analysis results of in vitro stability are shown in Figure 2. The retention time of ${ }^{99 \mathrm{~m}} \mathrm{Tc}[\mathrm{P}(\mathrm{VLA}-\mathrm{co}-\mathrm{VNI})](\text { tricine })_{2}$ was $11.9 \mathrm{~min}$ in our gradient. In vitro stability, the result measured by ITLC and HPLC, showed that ${ }^{99 \mathrm{~m}} \mathrm{Tc}[\mathrm{P}(\mathrm{VLA}-\mathrm{co}-\mathrm{VNI})](\text { tricine })_{2}$ could be stable over $4 \mathrm{~h}$ in saline at room temperature. Stability in murine plasma was also high; ${ }^{99 \mathrm{~m}} \mathrm{Tc}[\mathrm{P}(\mathrm{VLA}-\mathrm{co}-\mathrm{VNI})]$ (tricine) $)_{2}$ was still intact after $4 \mathrm{~h}$ at $37^{\circ} \mathrm{C}$. Furthermore, the dilutional stability was also investigated using a 1,000-fold dilution with freshly prepared murine plasma to more closely reproduce the situation in humans. After a 4-h incubation period at $37^{\circ} \mathrm{C}$, the RCP was still more than $92 \%$, as determined by ITLC.

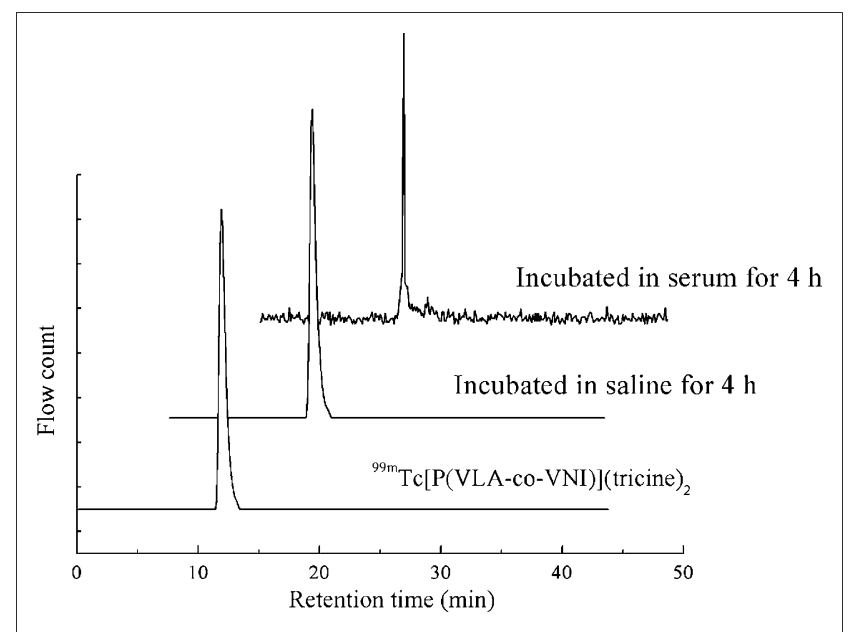

FIGURE 2. High-performance liquid chromatograms of $99 \mathrm{~m} T \mathrm{Tc}[\mathrm{P}$ (VLA-co-VNI)](tricine) 2 . Retention time was $11.9 \mathrm{~min}$ both after storage in saline at room temperature for $4 \mathrm{~h}$ and after incubation in murine plasma at $37^{\circ} \mathrm{C}$ for $4 \mathrm{~h}$, indicating the high stability of ${ }^{99 \mathrm{mTC}}$ $[\mathrm{P}(\mathrm{VLA}-\mathrm{co}-\mathrm{VNI})](\text { tricine })_{2}$ in vitro.

\section{Metabolic Stability}

The metabolic stability of ${ }^{99 \mathrm{~m}} \mathrm{Tc}[\mathrm{P}(\mathrm{VLA}-\mathrm{co}-\mathrm{VNI})](\text { tricine })_{2}$ was determined in mouse blood, liver, and urine samples. HPLC analysis results of blood, liver, and urine samples are shown in Figure 3. At 10 min after the injection of tracer, the small amount of ${ }^{99 \mathrm{~m}} \mathrm{Tc}[\mathrm{P}(\mathrm{VLA}-\mathrm{co}-\mathrm{VNI})](\text { tricine })_{2}$ that remained in the blood was still stable by HPLC analysis. The homogenate supernatant of liver samples at 10 and 120 min after injection showed a major radioactivity peak at $11.9 \mathrm{~min}$ on the high-performance liquid chromatogram, meaning most of the ${ }^{99 \mathrm{~m}} \mathrm{Tc}[\mathrm{P}(\mathrm{VLA}-\mathrm{co}-\mathrm{VNI})](\text { tricine })_{2}$ was intact and not metabolized in the liver within $2 \mathrm{~h}$. The HPLC retention time of the urinary metabolite was $18.8 \mathrm{~min}$, meaning no intact ${ }^{99 \mathrm{~m}} \mathrm{Tc}[\mathrm{P}(\mathrm{VLA}-\mathrm{co}-\mathrm{VNI})](\text { tricine })_{2}$ was excreted in the urine.

\section{Biodistribution}

To evaluate tissue distribution characteristics of ${ }^{99 \mathrm{~m}} \mathrm{Tc}[\mathrm{P}$ (VLA-co-VNI)](tricine) ${ }_{2}$, the biodistribution studies were performed using normal Kunming mice. The results are shown in Table 1. As described, ${ }^{99 \mathrm{~m}} \mathrm{Tc}[\mathrm{P}(\mathrm{VLA}-\mathrm{co}-\mathrm{VNI})]$ (tricine) ${ }_{2}$ had high liver accumulation, with good retention. The initial liver uptake was $125.32 \pm 10.99 \% \mathrm{ID} / \mathrm{g}$ at $10 \mathrm{~min}$ after injection. At 30 and $120 \mathrm{~min}$ after injection, the liver uptake was $122.64 \pm 9.06 \% \mathrm{ID} / \mathrm{g}$ and $114.74 \pm$ $9.93 \% \mathrm{ID} / \mathrm{g}$, respectively. The blood and kidneys showed relatively low activity. Even at $30 \mathrm{~min}$, the ratio of liver to blood uptake and liver to kidney uptake could reach 1,742 and 42 -a ratio obviously higher than that of ${ }^{99 \mathrm{~m} T c-G S A}$ (31.7 and 5.7, respectively, at $30 \mathrm{~min}$, in our experiments).

We selected both neogalactosylalbumin (known to have high affinity with the ASGP-Rs) and free cold P(VLA-coVNI) as inhibitors in our blocking study. Compared with the control group (without blocking), in both blocking groups the liver uptake was decreased significantly $(P<$ $0.01)$ at all selected time points. The difference in kidney accumulation between control and blocking groups was also statistically significant $(P<0.05)$. After blocking, the radioactivity in the blood increased only in the initial stages and eliminated rapidly from bloodstream after $30 \mathrm{~min}$. The results of biodistribution showed that the ${ }^{99 \mathrm{~m}} \mathrm{Tc}[\mathrm{P}(\mathrm{VLA}-\mathrm{co}-\mathrm{VNI})](\text { tricine })_{2}$ has high affinity with the ASGP-R, and its uptake in the liver is receptor-mediated.

\section{SPECT}

We also evaluated ${ }^{99 \mathrm{~m}} \mathrm{Tc}[\mathrm{P}(\mathrm{VLA}-\mathrm{co}-\mathrm{VNI})](\text { tricine })_{2}$ in vivo with SPECT. For the dynamic SPECT study, the regions of interest were drawn on the heart, liver, and kidneys, and the time-activity curves were calculated for these regions. An analysis of the time-activity curves (Fig. 4) shows that the liver uptake in the rabbit peaked within $2.5-5$ min after injection, whereas the radioactivity in the blood was decreased rapidly. The blocking study results showed that the uptake rate in the liver was significantly reduced and the clearance of radioactivity in the blood was significantly 
FIGURE 3. HPLC profiles of metabolic stability of $99 \mathrm{mTc}[\mathrm{P}(\mathrm{VLA}-\mathrm{Co}-\mathrm{VNI})](\text { tricine })_{2}$. Liver was collected at 10 and 120 min after injection of ${ }^{99 \mathrm{mTc}}[\mathrm{P}(\mathrm{VLA}-\mathrm{Co}-\mathrm{VNI})]$ (tricine $)_{2}$, blood was collected at 10 min after injection, and urine was collected at $120 \mathrm{~min}$

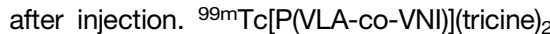
was intact in liver at 10 and 120 min after injection ( $A$ and $C$ ), with retention time of 11.9 min. Retention times of blood (B) and urine (D) samples were 11.9 and $18.8 \mathrm{~min}$, respectively.

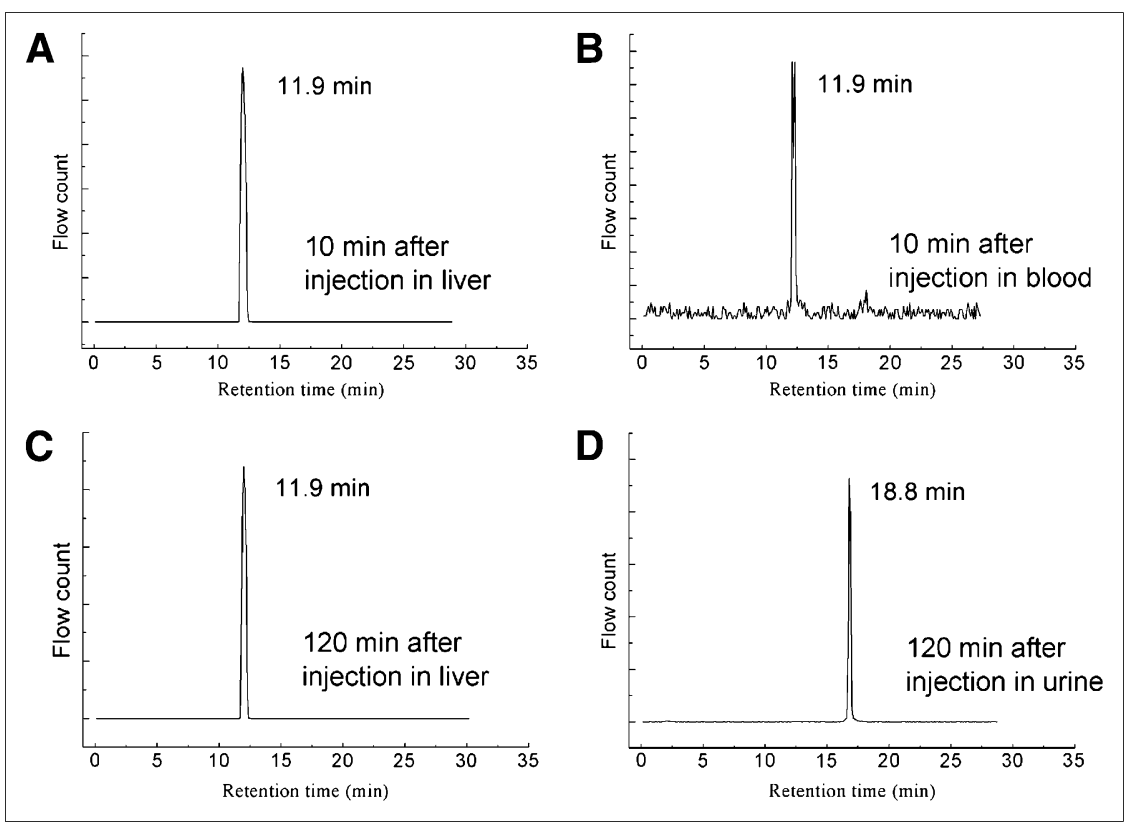

slower than that in the control group. The results also showed that a portion of radioactivity accumulated in and was metabolized via the kidneys after inhibition. Representative planar images are displayed in Figure 5. High liver activity accumulation was observed at $15 \mathrm{~min}$ after injection. There was no significant uptake in the kidneys, spleen, or other organs in the abdomen. A small portion of radioactivity was eliminated from the liver at later time points, and the outline of the liver was still clear. The abdominal radioactivity was increased slightly, indicating that the radioactivity was eliminated from the liver by hepatobiliary excretion as the major route. In contrast, after inhibition liver accumulation was significantly lower, and the outline of the liver was vague at $15 \mathrm{~min}$ (Fig. 5). After blocking, the cardiac level of activity was high, because of the nonspecific activity accumulated in the blood, and reduced gradually at later time points. The counts in the region of the liver accounted for $81 \%$ of the total radioactivity counts in the whole body at $30 \mathrm{~min}$ in the control group, whereas after inhibition the counts in the region of the liver were reduced to $41 \%$ of the total radioactivity counts in the whole body at $30 \mathrm{~min}$ after injection. We also found a high radioactivity concentration in the kidney and urinary bladder, and a gradual decrease in the uptake in the kidneys over time, indicating rapid clearance of the unbounded tracer through the kidneys after inhibition.

The potential of ${ }^{99 \mathrm{~m}} \mathrm{Tc}[\mathrm{P}(\mathrm{VLA}-\mathrm{co}-\mathrm{VNI})](\text { tricine })_{2}$ was also evaluated with the liver cancer model using SPECT/ CT. The SPECT/CT study was performed at $30 \mathrm{~min}$ after injection of ${ }^{99 \mathrm{~m}} \mathrm{Tc}[\mathrm{P}(\mathrm{VLA}-\mathrm{co}-\mathrm{VNI})](\text { tricine })_{2}$. As shown in Figure 6, the tumor site in the rabbit's liver could be clearly visualized, despite the use of a clinical SPECT/CT scanner. Minor errors in superimposition of SPECT and CT data may be due to involuntary respiratory and bowel move- ment. The tumor was confirmed by pathologic examination after the imaging study (Supplemental Fig. 2).

\section{DISCUSSION}

Measurement of hepatic functional reserve could be useful before hepatectomy and for the evaluation of posttransplantation residual hepatic functional reserve in donors (25). The number of ASGP-Rs on the hepatocytes of patients with liver disease is reduced and thus considered a good indicator for the evaluation of liver function (26). Noninvasive quantification of the liver uptake of radiolabeled asialoglycoproteins can provide a unique way to estimate liver function, especially in terms of spatial distribution of hepatic function (27-29). ${ }^{99 m}$ Tc-labeled synthetic asialoglycoproteins such as neogalactosylalbumin and GSA were developed as ASGP-R imaging agents. ${ }^{99 \mathrm{~m}} \mathrm{Tc}-\mathrm{GSA}$ is used clinically and is at this time commercially available only in Japan. Those ASGP-R imaging agents using albumin as the backbone have encountered problems. There is a risk of viral breakthrough for the blood products of HSA, and therefore these products are closely regulated during good manufacturing practice and importation. A newly designed probe with nonalbumin backbone could avoid this problem. In addition, because of the natural properties of albumin those tracers using albumin as the backbone usually have high stability in the bloodstream and a long circulation time, which is unfavorable for cold area imaging in liver. Especially in patients with severe liver diseases, the liver images could be rather vague. Moreover, other problems exist, such as sensitivity to changes of temperature and $\mathrm{pH}$ and the introduction of toxic byproducts during synthesis. Recently, radiotracers using chitosan or dextran as the backbone were developed (4,17-19). Those tracers showed specific and rapid targeting of hepatocytes. However, the tracers using 
chitosan as the backbone show high renal uptake, limiting their clinical applications for hepatic imaging. To overcome these problems, we developed a new ASGP-R agent using PVLA as the backbone by incorporating hydrazinonicotinamide-functionalized groups for radiolabeling with ${ }^{99 \mathrm{~m}} \mathrm{Tc}$. Hydrazinonicotinamide is an attractive bifunctional coupling agent for preparing ${ }^{99 \mathrm{~m}} \mathrm{Tc}-$ labeled antibodies, peptides, and small biomolecules (30). We synthesized P(VLAco-VNI) through polymerization of 2 monomers, VLA and VNI, with good yield and easy purification. This approach is feasible for introducing bifunctional coupling agents for the polymer radiopharmaceutical. At the same time, through copolymerization of a variety of different monomers, we could introduce affinity ligands, bifunctional groups, or organic dye, affording a potential method to prepare pharmaceuticals for targeted molecular imaging or even multifunction imaging.

${ }^{99 \mathrm{~m}} \mathrm{Tc}[\mathrm{P}(\mathrm{VLA}-\mathrm{co}-\mathrm{VNI})](\text { tricine })_{2}$ showed promising properties in preliminary biologic experiments and characteristics different from ${ }^{99 \mathrm{~m} T c-G S A}$. There are at least 2 processes after ${ }^{99 \mathrm{~m}} \mathrm{Tc}-\mathrm{GSA}$ enters the hepatocyte. First, the endocytosed receptor and ligand dissociate in lysosomes. The receptor recycles to the cell surface. Then, the backbone of ${ }^{99} \mathrm{~m}$ Tc-GSA is degraded to yield DTPA-coupled lysine ( ${ }^{99 m}$ Tc-DTPA-lysine) in lysosome and is slowly released from the cell $(31,32)$. Similar to results with GSA, in our blocking experiments, the results of blockage were comparable using neogalactosylalbumin or P(VLA-co-VNI) as an inhibitor. After blocking, the radioactivity in the liver was increased gradually at the later time after injection, likely reflecting dissociation of the receptor and ligand (both neogalactosylalbumin and P(VLA-co-VNI)) and leading to the recycling of ASGP-Rs to the surface membrane. Furthermore, we investigated the metabolic stability of ${ }^{99 \mathrm{~m}} \mathrm{Tc}[\mathrm{P}$ (VLA-co-VNI)](tricine) ${ }_{2}$ in the liver. No or little radiotracer was degraded in the liver for at least $2 \mathrm{~h}$. On the basis of the results of our blocking experiment and metabolic studies, we hypothesized that ${ }^{99 \mathrm{~m}} \mathrm{Tc}[\mathrm{P}(\mathrm{VLA}-\mathrm{co}-\mathrm{VNI})](\text { tricine })_{2}$ would be rapidly taken up by hepatocytes via ASGP-R-mediated endocytosis. Then the receptor-ligand complex was dissociated in lysosomes. The ASGP-Rs circulated to the surface of the cell membrane, whereas the intact ligand remained in the hepatocytes metabolized slowly. Because the protein backbone could be degraded in lysosomes, the biologic properties display a marked difference when adopting different bifunctional groups in a protein-based ASGP-R targeting agent (15). In contrast, the bifunctional groups in this copolymer-based ASGP-R targeting agent may have only a minor impact on biodistribution because of the high stability of the copolymer backbone in the liver.

Furthermore, the in vivo SPECT evaluation of ${ }^{99 \mathrm{~m}} \mathrm{Tc}[\mathrm{P}$ (VLA-co-VNI)](tricine $)_{2}$ was observed in rabbits with high liver accumulation and good retention. The high radioactivity concentration in the urinary bladder after blocking indicated rapid clearance of the unbounded tracer through the kidney. The fact that ${ }^{99 \mathrm{~m}} \mathrm{Tc}[\mathrm{P}(\mathrm{VLA}-\mathrm{co}-\mathrm{VNI})](\text { tricine })_{2}$ 

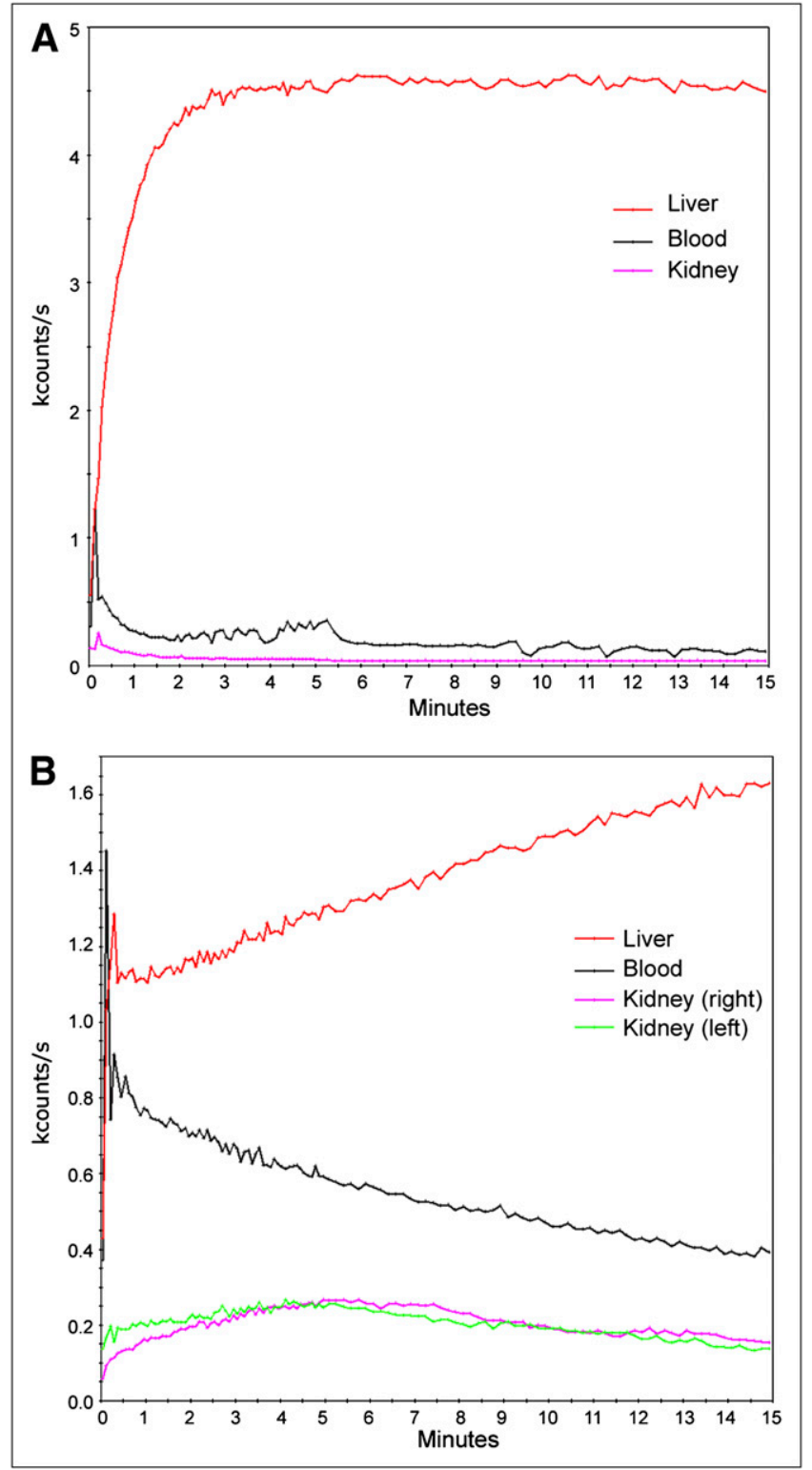

FIGURE 4. Time-activity curves obtained from 15-min dynamic planar acquisition. (A) In normal rabbit, liver uptake peaked rapidly within 2.5-5 min, whereas radioactivity in blood decreased rapidly. (B) In blocking study, uptake rate in liver was significantly reduced by preinjected neogalactosylalbumin. Uptake in blood and kidneys was relatively high and decreased continuously over time.

had a short circulation time in the bloodstream could reduce the level of radioactivity in the hepatic blood pool and other vascularized organs. Thus, SPECT images with ambiguity caused by high radioactivity in blood, especially for the patients with severe liver disease, could be avoided when using ${ }^{99 \mathrm{~m}} \mathrm{Tc}[\mathrm{P}(\mathrm{VLA}-\mathrm{co}-\mathrm{VNI})]$ (tricine $)_{2}$. The clear SPECT images of the liver were obtained both in the blocking group at $30 \mathrm{~min}$ after injection and in the rabbits with liver cancer. The novel tracer ${ }^{99 \mathrm{~m}} \mathrm{Tc}[\mathrm{P}(\mathrm{VLA}-\mathrm{co}-\mathrm{VNI})]$ (tricine) $)_{2}$ shows good biologic properties that may provide clear images and detailed information. Moreover, ${ }^{99} \mathrm{~m} \mathrm{Tc}[\mathrm{P}(\mathrm{VLA}-$

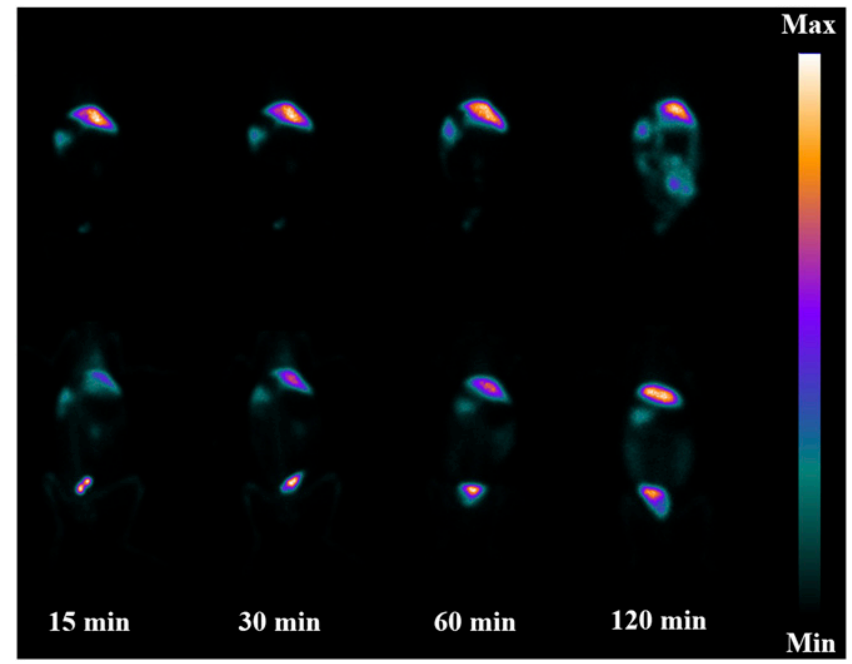

FIGURE 5. Planar images of rabbit. The upper row is control group; lower row is blocking group with free neogalactosylalbumin as blocking agent (10 mg/kg of rabbit body weight). Times are times after injection.

co-VNI)](tricine $)_{2}$ can be easy to formulate using a kit, making it possible for clinical applications in the future.

\section{CONCLUSION}

A receptor-specific ligand for the ASGP-R was developed via copolymerization. The bifunctional coupling agent hydrazinonicotinamide was introduced to a galactosecarrying polystyrene derivative. The copolymer P(VLAco-VNI) was labeled with ${ }^{99 \mathrm{~m}} \mathrm{Tc}$, with high labeling yield. Biodistribution and imaging studies demonstrated hepatic targeting and rapid blood clearance for this tracer. ${ }^{99 \mathrm{~m}} \mathrm{Tc}[\mathrm{P}$ (VLA-co-VNI)] (tricine) ${ }_{2}$ accumulated mainly in the liver. Clear images can be obtained using ${ }^{99 \mathrm{~m}} \mathrm{Tc}[\mathrm{P}$ (VLA-co$\mathrm{VNI})$ (tricine) ${ }_{2}$ because of the high liver-to-background ratio of the copolymer. The promising biologic properties of ${ }^{99 \mathrm{~m}} \mathrm{Tc}[\mathrm{P}(\mathrm{VLA}-\mathrm{co}-\mathrm{VNI})](\text { tricine })_{2}$ afford potential applications for assessment of hepatocyte function in the future. In addition, the synthesis process could enable efficient modification of copolymers with other ligands and bifunctional coupling agents for nuclear medicine imaging of different targets.

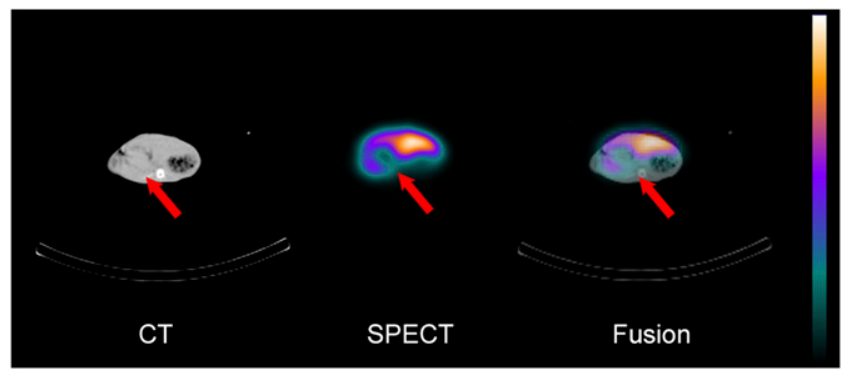

FIGURE 6. SPECT/CT for detection and localization of liver cancer. Liver is visualized as transaxial sections at $30 \mathrm{~min}$ after injection merged with CT and SPECT images. Arrows indicate site of tumor. 


\section{DISCLOSURE STATEMENT}

The costs of publication of this article were defrayed in part by the payment of page charges. Therefore, and solely to indicate this fact, this article is hereby marked "advertisement" in accordance with 18 USC section 1734.

\section{ACKNOWLEDGMENTS}

We thank Dr. Yong He for his kind donation of dextran standards and Dr. Wei Fang, Wenyan Guo, Huihui Jing, and Zuoquan Zhao for their generous help. The project was sponsored by the Fundamental Research Funds for the Central Universities and supported partially by the National Natural Science Foundation of China (20871020), Beijing Natural Science Foundation (2092018), and the Scientific Research Foundation for the Returned Overseas Chinese Scholars, State Education Ministry.

\section{REFERENCES}

1. Kokudo N, Vera DR, Makuuchi M. Clinical application of TcGSA. Nucl Med Biol. 2003;30:845-849.

2. Stadalnik RC, Vera DR. The evolution of ${ }^{99 m}$ Tc-NGA as a clinically useful receptor-binding radiopharmaceutical. Nucl Med Biol. 2001;28:499-503.

3. Saha GB. Fundamentals of Nuclear Pharmacy. 4th ed. New York, NY: Springer New York; 1998.

4. Kim EM, Jeong HJ, Kim SL, et al. Asialoglycoprotein-receptor-targeted hepatocyte imaging using Tc-99m galactosylated chitosan. Nucl Med Biol. 2006;33: 529-534.

5. de Graaf W, Bennink RJ, Vetelainen R, van Gulik TM. Nuclear imaging techniques for the assessment of hepatic function in liver surgery and transplantation. J Nucl Med. 2010;51:742-752.

6. Vera DR, Stadalnik RC, Krohn KA. Technetium-99m galactosyl-neoglycoalbumin: preparation and preclinical studies. J Nucl Med. 1985;26:1157-1167.

7. Kubota Y, Kojima M, Hazama $\mathrm{H}$, et al. A new liver function test using the asialoglycoprotein-receptor system on the liver cell membrane: I. Evaluation of liver imaging using Tc-99m-neoglycoprotein [in Japanese]. Kaka Igaku. 1986;23:899-905.

8. Ono M, Arano $\mathrm{Y}$, Uehara $\mathrm{T}$, et al. Intracellular metabolic fate of radioactivity after injection of technetium-99m-labeled hydrazino nicotinamide derivatized proteins. Bioconjug Chem. 1999;10:386-394.

9. Yang W, Mou T, Zhang X, Wang X. Synthesis and biological evaluation of 99m Tc-DMP-NGA as a novel hepatic asialoglycoprotein receptor imaging agent. Appl Radiat Isot. 2010;68:105-109.

10. Chaumet-Riffaud P, Martinez-Duncker I, Marty A-L, et al. Synthesis and Application of lactosylated, ${ }^{99 \mathrm{~m}} \mathrm{Tc}$ chelating albumin for measurement of liver function. Bioconjug Chem. 2010;21:589-596.

11. Jeong JM, Hong MK, Lee J, et al. Tc-99m-neolactosylated human serum albumin for imaging the hepatic asialoglycoprotein receptor. Bioconjug Chem. 2004; 15:850-855.

12. Wakisaka K, Arano $\mathrm{Y}$, Uezono $\mathrm{T}$, et al. A novel radioiodination reagent for protein radiopharmaceuticals with L-lysine as a plasma-stable metabolizable linkage to liberate m-iodohippuric acid after lysosomal proteolysis. J Med Chem. 1997;40:2643-2652.

13. Arano Y, Mukai T, Akizawa H, et al. Radiolabeled metabolites of proteins play a critical role in radioactivity elimination from the liver. Nucl Med Biol. 1995;22: $555-564$.

14. Vera DR. Gallium-labeled deferoxamine-galactosyl-neoglycoalbumin: a radiopharmaceutical for regional measurement of hepatic receptor biochemistry. J Nucl Med. 1992;33:1160-1166.

15. Yang W, Mou T, Peng C, et al. Fluorine-18 labeled galactosyl-neoglycoalbumin for imaging the hepatic asialoglycoprotein receptor. Bioorg Med Chem. 2009;17: 7510-7516.

16. Park I-K, Yang J, Jeong H-J, et al. Galactosylated chitosan as a synthetic extracellular matrix for hepatocytes attachment. Biomaterials. 2003;24:2331-2337.

17. Vera DR, Hall DJ, Hoh CK, Gallant P, McIntosh LM, Mattrey RF. Cy5.5-DTPAgalactosyl-dextran: a fluorescent probe for in vivo measurement of receptor biochemistry. Nucl Med Biol. 2005;32:687-693.

18. Kim EM, Jeong HJ, Park IK, Cho CS, Kim CG, Bom HS. Hepatocyte-targeted nuclear imaging using Tc-99m-galactosylated chitosan: conjugation, targeting, and biodistribution. J Nucl Med. 2005;46:141-145.

19. Yang W, Mou T, Guo W, et al. Fluorine-18 labeled galactosylated chitosan for asialoglycoprotein-receptor-mediated hepatocyte imaging. Bioorg Med Chem Lett. 2010;20:4840-4844.

20. Hiratsuka T, Goto M, Kondo Y, Cho CS, Akaike TR. Copolymers for hepatocytespecific targeting carrying galactose and hydrophobic alkyl groups. Macromol Biosci. 2008;8:231-238.

21. Mitsuaki G, Hirohumi Y, Chia-Wun C, et al. Lactose-carrying polystyrene as a drug carrier: investigation of body distributions to parenchymal liver cells using ${ }^{125}$ I-labelled lactose-carrying polystyrene. J Control Release. 1994;28: $223-233$.

22. Kobayashi K, Sumitomo H, Ina YA. Carbohydrate-containing synthetic polymer obtained from N-p-vinylbenzyl-D-gluconamide. Polym J. 1983;15:667-671.

23. Kobayashi K, Sumitomo H, Ina Y. Synthesis and functions of polystyrene derivatives having pendant oligosaccharides. Polym J. 1985;17:567-575.

24. Harris TD, Sworin M, Williams N, et al. Synthesis of stable hydrazones of a hydrazinonicotinyl-modified peptide for the preparation of ${ }^{99 \mathrm{~m}} \mathrm{Tc}-$ labeled radiopharmaceuticals. Bioconjug Chem. 1999;10:808-814.

25. Clavien PA, Petrowsky H, DeOliveira ML, Graf R. Strategies for safer liver surgery and partial liver transplantation. N Engl J Med. 2007;356:1545-1559.

26. Stockert RJ. The asialoglycoprotein receptor: relationships between structure, function, and expression. Physiol Rev. 1995;75:591-609.

27. Hwang E-H, Taki J, Shuke N, et al. Preoperative assessment of residual hepatic functional reserve using ${ }^{99 \mathrm{~m}}$ Tc-DTPA-galactosyl-human serum albumin dynamic SPECT. J Nucl Med. 1999;40:1644-1651.

28. Sugai Y, Komatani A, Hosoya T, Yamaguchi K. Response to percutaneous transhepatic portal embolization: new proposed parameters by ${ }^{99 \mathrm{~m} T c-G S A}$ SPECT and their usefulness in prognostic estimation after hepatectomy. J Nucl Med. 2000;41:421-425

29. Shuke N, Okizaki A, Kino S, et al. Functional mapping of regional liver asialoglycoprotein receptor amount from single blood sample and SPECT. J Nucl Med. 2003;44:475-482.

30. Liu S. 6-hydrazinonicotinamide derivatives as bifunctional coupling agents for ${ }^{99 \mathrm{~m}} \mathrm{Tc}$-labeling of small biomolecules. In: Topics in Current Chemistry, Contrast Agents III. Heidelberg, Germany: Springer Berlin; 2005:117-153.

31. Duncan JR, Welch MJ. Intracellular metabolism of indium-111-DTPA-labeled receptor targeted proteins. J Nucl Med. 1993;34:1728-1738.

32. Arano Y, Mukai T, Uezono T, et al. A biological method to evaluate bifunctional chelating agents to label antibodies with metallic radionuclides. $\mathrm{J} \mathrm{Nucl} \mathrm{Med}$. 1994;35:890-898. 